\title{
Stereotactic radiosurgery for Cushing disease
}

\author{
Stephen J. Hentschel, M.D., F.R.C.S.(C), and Ian E. MCCutcheon, M.D., F.R.C.S.(C) \\ Department of Neurosurgery, The University of Texas M. D. Anderson Cancer Center, Houston, Texas
}

\begin{abstract}
The most common cause of Cushing syndrome is Cushing disease, in which hypercortisolism is produced by a functional adrenocorticotropic hormone-producing adenoma of the anterior pituitary gland. The common therapies available include microsurgical resection, conventional fractionated radiotherapy, and stereotactic radiosurgery (SRS). In this article the authors review the indications, results, and complications associated with SRS in the treatment of Cushing disease.

In as many as $90 \%$ of patients SRS results in disease remission, which is defined as a normal 24-hour urinary free cortisol level and a normal or subnormal morning serum cortisol level. Although in most patients who are subsequently cured a marked decrease in the serum cortisol level is demonstrated within 3 months after treatment, a biochemical cure may be delayed up to 3 years in some cases. Complications following SRS for pituitary adenomas are uncommon, particularly in patients with microadenomas, which are most commonly seen in Cushing disease. The most common complication is hypopituitarism, which occurs in up to $50 \%$ of patients with a mean latency period of 5 years. Radiation-induced optic neuropathy has been reported in less than $2 \%$ of cases and induction of a secondary neoplasm in less than $1 \%$ of cases.

For patients with Cushing disease, the rate of endocrinological cure following SRS appears to be similar to that attained using microsurgical resection. In contrast to surgery, SRS has the benefit of being noninvasive and associated with a very low incidence of diabetes insipidus, although hypopituitarism may be more common with SRS. With continued follow-up patient reviews and additional experience with SRS, it may become possible to make more definitive statements regarding SRS as the initial treatment for patients with Cushing disease.
\end{abstract}

\section{KEY WORDS • Cushing disease • pituitary adenoma • stereotactic radiosurgery}

Cushing syndrome is a well-known constellation of signs and symptoms produced by an excessive level of cortisol that is either endogenously secreted or exogenously administered. The most common cause of this syndrome is Cushing disease, in which an adenoma of the anterior pituitary gland that secretes ACTH stimulates the synthesis of cortisol by the adrenal gland; this accounts for up to $80 \%$ of all cases of Cushing syndrome (Fig. 1). ${ }^{24}$ The morbidity associated with Cushing syndrome may be severe with multiple organ systems affected; the mortality rate associated with this syndrome, if left untreated, has been reported to be $50 \%$ within 5 years. ${ }^{38}$

Therapeutic options include microsurgical resection, conventional radiotherapy, chemotherapy, and SRS. Microsurgical resection remains the proven primary therapy; it has a long-term cure potential and a low incidence of complications when current microneurosurgical techniques are used. Nevertheless, cures following resection range between 64 and 93\% of cases and surgical cures for invasive adenomas are infrequent. ${ }^{2,16,24,29,43,45}$ Although conventional fractionated radiotherapy is also effective in reducing the hypercortisolemia of Cushing disease, there may be a significant delay of up to several years follow-

Abbreviations used in this paper: $\mathrm{ACTH}=$ adrenocorticotropic hormone; $\mathrm{CT}=$ computerized tomography; MR = magnetic resonance; $\mathrm{RON}=$ radiation-induced optic neuropathy; $\mathrm{SRS}=$ stereotactic radiosurgery. ing radiotherapy for a beneficial clinical and biochemical effect. Conventional radiotherapy also results in irradiation of critical intracranial structures, such as the temporal lobes and optic apparatus and is associated with at least a $50 \%$ long-term incidence of hypopituitarism. ${ }^{27,37}$ Because agents such as bromocriptine or inhibitors of steroidogenesis are used, chemotherapy is reserved for adjuvant therapy of treatment-resistant Cushing disease or for the occasional mild form of the disease, which responds to these medications.

Stereotactic radiosurgery was developed in Sweden in 1969 by Lars Leksell and has been used in the treatment of ACTH-producing adenomas since that time. Despite its widespread use in Sweden, this technique did not become a viable therapeutic option in many other countries until the 1980s.

\section{STEREOTACTIC RADIOSURGERY}

Stereotactic radiosurgery can be administered using either a linear accelerator or gamma knife system. Both forms of radiosurgery are based on similar principles of delivering focused radiation to intracranial targets while sparing normal structures, but they differ in the type of radiation that is delivered and in their targeting technologies. Radiosurgery has become a valuable option as a primary therapy for many neurosurgical problems because it is minimally invasive, takes relatively little time to admin- 


\section{S. J. Hentschel and I. E. McCutcheon}

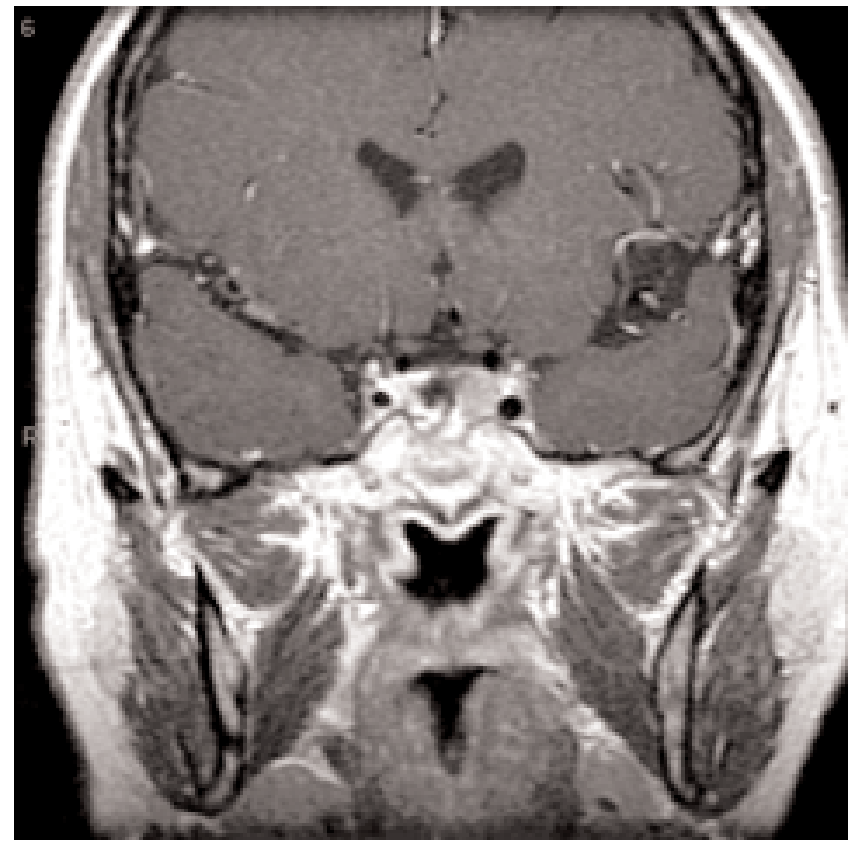

Fig. 1. Coronal contrast-enhanced MR image of the sella turcica in a patient with recurrent Cushing disease. There is a well-circumscribed 7-mm-wide lesion in the left lateral aspect of the pituitary gland. This lesion is suitable for SRS treatment.

ister (often in only one session), can be performed in an outpatient setting, and has few acute side effects. As experience with radiosurgery continues to grow, questions regarding long-term efficacy and potential complications, such as the induction of secondary neoplasms, will be answered.

Several problems, both practical and theoretical, face the radiosurgeon. Although some of these problems apply to radiosurgery in general, others are specific to the treatment of Cushing disease (Table 1). In most of the oncology literature regarding the relative success of radiosurgery the authors rely on tumor control as the primary measure, which means that a lack of increase in tumor size is indicative of successful treatment. Absence of tumor growth for ACTH-producing adenomas is not an appropriate measure of successful therapy because persistent hypercortisolemia may cause ongoing morbidity. Thus, cure rather than control is the goal of therapy in patients with Cushing disease and this is measured by biochemical means. In the older literature on this disease, definitions of "cure" or "remission" were not standardized. Normal or subnormal levels of 24-hour urinary free cortisol and morning serum cortisol are probably the most appropriate and practical measures of a cure, although a normal plasma level of ACTH or a normal response to the dexamethasone suppression test have been added by some authors. . $^{18,32,40,46}$

Deciding the most appropriate dose of radiation can be confusing, and the choices physicians make complicate a comparison of patient outcomes from different centers. Older studies of SRS focused on maximal tumor doses. Evidence from nonpituitary lesions treated with SRS has indicated that the radiation dose directed to the tumor margin is more important in determining the relative treatment
TABLE 1

Problems facing the radiosurgeon when treating patients with Cushing disease

\begin{tabular}{ll}
\hline \hline No. & \multicolumn{1}{c}{ Problem } \\
\hline $1 \quad$ What is the appropriate measure of success? \\
Is it growth control? \\
Is it biochemical cure? \\
$2 \quad$ What is the definition of cure for Cushing disease? \\
$3 \quad$ What is the appropriate radiosurgical dose? \\
$\quad$ Is it the maximal dose or the dose to the tumor margin that is important? \\
\hline
\end{tabular}

success, ${ }^{11,19}$ but this has not been shown conclusively for pituitary adenomas. In patients with Cushing disease, both maximal $^{40}$ and margin ${ }^{22}$ radiation doses have been reported to be statistically significant predictors of success.

Finally, targeting of ACTH-producing adenomas by using CT-guided technology may not provide enough resolution to identify the microadenomas typical of Cushing disease. The distinct identification of the radiosurgical target may require fusion with MR images or an MR imaging-based targeting system, both of which may introduce inaccuracies in targeting. In addition, in up to $17 \%$ of patients with Cushing disease no demonstrable intrasellar abnormality is apparent, even on high-resolution MR images. ${ }^{43}$ The radiosurgical literature contains no study of the utility of SRS in the treatment of patients with occult adenomas, that is, those patients in whom no abnormality appears on imaging to be targeted. Nevertheless, there have been reports of radiosurgery-induced hypophysectomy for the treatment of cancer pain in patients in whom doses in the range of 150 to 200 Gy were administered with one or two isocenters targeting the pituitary stalk. ${ }^{17}$ As a result of the morbidity associated with persistent hypercortisolemia, radiosurgical hypophysectomy may be a viable option in patients with severe Cushing disease in whom definite imaging abnormality is lacking and the disease has been refractory to standard therapies (Fig. 2). In this circumstance in particular, the correct diagnosis and the appropriate biochemical demonstration of a pituitary source of hypercortisolemia are critical before embarking on any treatment for Cushing disease.

\section{Results of SRS}

As mentioned previously, biochemical remission without associated complications is the goal of therapy in patients with Cushing disease. Remission rates after surgery have been reported and microsurgical resection remains the proven primary therapy because it produces an immediate beneficial effect following successful surgery. Surgical cures for recurrent or invasive adenomas are less common than those for typical ACTH-producing adenomas, however, prompting a need for effective adjuvant therapies. Although conventional radiotherapy results in up to a $90 \%$ remission rate by 5 years posttreatment, ${ }^{8}$ if followed long enough a large proportion of patients begin to experience hypopituitarism and approximately $5 \%$ of patients experience an RON, which is very difficult to treat effectively. ${ }^{1,27,48}$ Stereotactic radiosurgery has the advantages of a rapid onset of therapeutic benefit, similar to surgery, and a minimally invasive nature, similar to radio- 


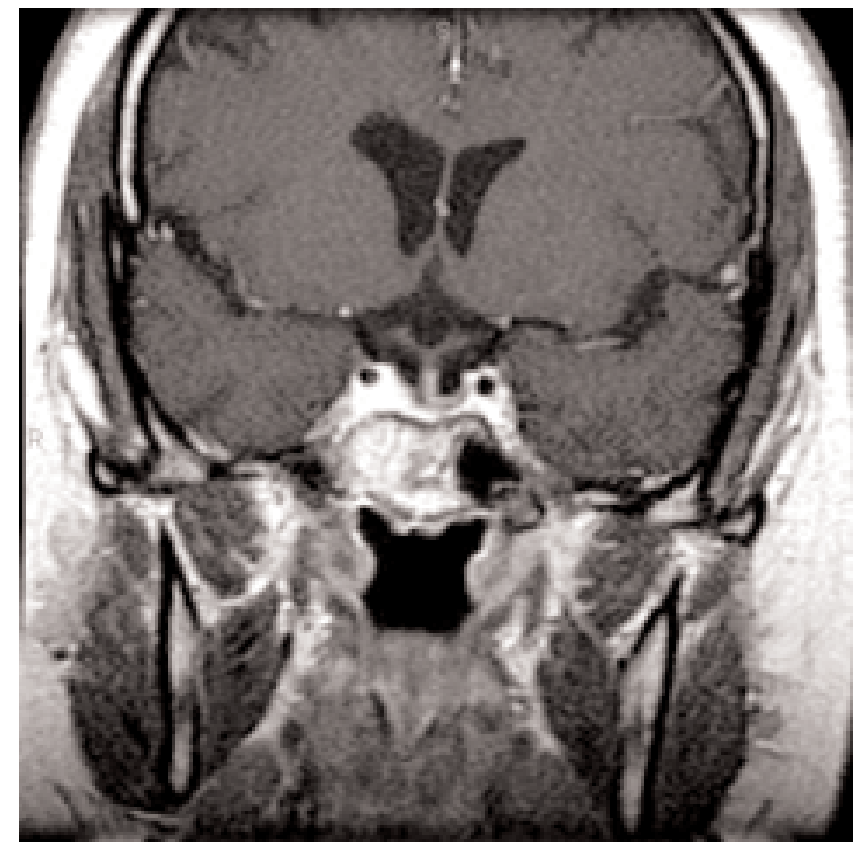

Fig. 2. Coronal contrast-enhanced MR image obtained in a patient with recurrent Cushing disease, which previously was treated with transsphenoidal resection and fractionated radiotherapy. No discrete adenoma is seen, but the patient may be a candidate for SRS if the Cushing disease is severe and the biochemical workup indicates that the sella turcica is the source of ACTH hypersecretion.

therapy. Table 2 provides some details in the literature on the cures, complications, and latency periods for microsurgical resection, conventional radiotherapy, and SRS.

Early results of radiosurgical treatment of ACTH-producing adenomas were encouraging, even though until approximately 1980 neurosurgeons were limited to using pneumoencephalography for outlining the lesions to be treated. Degerblad, et al., ${ }^{7}$ reported their results in 35 patients with Cushing disease who were treated between 1975 and 1982 at Karolinska Hospital by using pneumoencephalography-based radiosurgery. Treatment was administered using an early version of the Gamma Knife. ${ }^{7}$ Of the 29 patients who were followed up for longer than 3 years, disease remission was achieved in $14(48 \%)$ after a single maximal dose of radiosurgery, which ranged between 70 and $100 \mathrm{~Gy}$. An additional eight patients experienced remission of their disease after undergoing between one and three radiosurgical procedures, for a total of 22 patients $(76 \%)$ in biochemical remission. Disease remissions occurred in approximately $50 \%$ of the patients within 1 year and in the other $50 \%$ within 3 years. No recurrences or complications were reported. Pituitary insufficiency eventually developed in $55 \%$ of the patients between 4 months and 7 years post-SRS.

Hoybye, et al., ${ }^{18}$ provided additional long-term followup data on patients with ACTH-producing adenomas who were treated at Karolinska Hospital between 1976 and 1985. Unfortunately, of the 89 patients treated with SRS for Cushing disease, detailed data were only available in 18. Overall, $83 \%$ of patients experienced remission of their disease after a mean follow-up period of 17 years, with $44 \%$ enjoying remission after one session of SRS and
TABLE 2

Literature review for incidence of endocrinological cure and hypopituitarism following resection, conventional radiotherapy, and SRS for ACTH-producing adenomas

\begin{tabular}{|c|c|c|c|c|}
\hline \multirow[b]{2}{*}{ Therapy, Authors \& Year } & \multicolumn{2}{|c|}{ Cure } & \multicolumn{2}{|c|}{ Hypopituitarism } \\
\hline & Rate $(\%)$ & $\begin{array}{l}\text { Latency } \\
\text { Period }\end{array}$ & Rate $(\%)$ & $\begin{array}{l}\text { Latency } \\
\text { Period }\end{array}$ \\
\hline $\begin{array}{l}\text { surgery } \\
\text { Guilhaume, et al., } 1988 \\
\text { Mampalam et al., } 1988 \\
\text { Burke, et al., } 1990 \\
\text { Trainer, et al., } 1993 \\
\text { Bochicchio, et al., } 1995 \\
\text { Ciric, et al., 1997 } \\
\text { Laws, et al., } 2002\end{array}$ & $64-93$ & immediate & $2-48$ & early \\
\hline $\begin{array}{l}\text { conventional radiotherapy } \\
\text { Littley, et al., } 1989 \\
\text { Estrada, et al., } 1997 \\
\text { Petrovich, et al., } 2003\end{array}$ & 90 & $\leq 5 \mathrm{yrs}$ & 50 & $\begin{array}{l}\text { months- } \\
\text { many } \\
\text { years }\end{array}$ \\
\hline $\begin{array}{l}\text { radiosurgery } \\
\quad \text { Degerblad, et al., } 1986 \\
\text { Hoybye, et al., } 2001 \\
\text { Feigl, et al., 2002 } \\
\text { Kobayashi, et al., } 2002 \\
\text { Pollock, et al., 2002 } \\
\text { Vladyka, et al., } 2003\end{array}$ & $35-90$ & $\begin{array}{r}3 \text { mos- } \\
3 \text { yrs }\end{array}$ & $16-55$ & $\begin{array}{l}\text { 50-60 } \\
\text { months } \\
\text { (median) }\end{array}$ \\
\hline
\end{tabular}

$39 \%$ after between two and four treatments in which a dose of 30 to 35 Gy was delivered to the tumor margin. Again, there were no instances of recurrence. Significantly, it was found that the most marked decrease in cortisol occurred within 3 months after treatment; if the urinary free cortisol level was not less than $500 \mathrm{nmol} / \mathrm{L}$ by 3 months, a subsequent remission was unlikely. In this study, $69 \%$ of patients experienced hypothyroidism and all patients had growth hormone deficiency, but no other morbid state was reported.

In a study from Japan, Kobayashi, et al., ${ }^{22}$ reported on 20 of 25 patients with Cushing disease who underwent gamma knife surgery. These authors evaluated both tumor size and endocrine results posttreatment with a mean follow-up period of 64 months. The mean dose to the tumor margin was 29 Gy and there was a mean of 3.8 isocenters per patient. Among the 20 patients, there was complete resolution of the tumor on MR images in six patients $(30 \%)$, a greater than $50 \%$ of decrease in the size of the lesion in $11(55 \%)$, a 25 to $50 \%$ decrease in the size of the lesion in two (10\%), and no change in one patient $(5 \%)$. Levels of ACTH and cortisol became normal in seven patients $(35 \%)$, were significantly decreased in five $(25 \%)$, were somewhat decreased in five $(25 \%)$, and did not change in three $(15 \%)$. No mention was made of morbidity, although an unfavorable outcome was reported for five patients (25\%), including one who died. In this study, the predictors of a complete tumor response (disappearance of the lesion on MR images) were a radiosurgical target lower than $10 \mathrm{~mm}$ in diameter and a radiation dose greater than $40 \mathrm{~Gy}$ directed to the tumor margin.

In a series of 59 patients with functional pituitary adenomas, which included nine patients with Cushing disease treated at the Mayo Clinic, Pollock, et al., ${ }^{40}$ found that $78 \%$ of patients with ACTH-producing adenomas were 
cured following gamma knife surgery; the cure was established by findings of a 24-hour urinary free cortisol level lower than $90 \mu \mathrm{g}$ during a mean follow-up period of 40 months. Predictors of failure determined by a multivariate analysis included the use of preoperative hormone-suppressive medications and a maximal (as opposed to margin) radiosurgical dose lower than $40 \mathrm{~Gy}$. This maximal dose of 40 Gy likely represents a dose of 20 Gy to the tumor margin, which is substantially less than that reported by the groups from Sweden. ${ }^{7,18}$ Nevertheless, it is probable that the good outcomes attained by Pollock, et al.,40 were related to significantly better targeting capabilities afforded by CT and MR imaging than existed with pneumoencephalography. Also in contrast to the studies discussed previously, this group rigorously reported incidences of morbidity. The overall incidence of morbidity was $26 \%$, with $16 \%$ of patients having new hormonal deficits, $3 \%$ harboring radionecrosis of the temporal lobe, and $2 \%$ experiencing visual loss. These morbidity rates were reported for the whole group of patients with functional pituitary adenomas and not just for those with ACTH-producing adenomas.

Other authors have recommended SRS for the treatment of ACTH-producing adenomas that persist after noncurative surgical treatment and for recurrent Cushing disease. ${ }^{24,46}$ In a study of 65 patients with Cushing disease in whom surgery failed to produce a cure, 40 patients were followed up for more than 12 months; Laws, et al., ${ }^{24}$ found that 24-hour urinary free cortisol and morning cortisol levels normalized in $74 \%$ of these patients a mean of 16 months after radiosurgical treatment. In this study, there was an $8 \%$ recurrence rate between 19 and 38 months after therapy, and a $24 \%$ incidence of new endocrine deficits. The dose of radiation did not correlate with the biochemical outcome, nor was there any correlation between the preoperative size of the tumor and the endocrine outcome. . $^{14,39,46}$

\section{Complications of SRS}

Complications after SRS for pituitary adenomas do occur, but are less common in patients with microadenomas. The most significant complications following irradiation of the pituitary region are RON, temporal lobe necrosis, induction, of a secondary neoplasm, and hypopituitarism. In contrast to surgery, in which the risk of diabetes insipidus is approximately $18 \%,{ }^{5}$ this risk appears to be negligible with SRS. The incidence of RON following conventional radiotherapy is $5 \%,{ }^{13,27}$ but it is less than $2 \%$ after SRS when all tumors, including macroadenomas, are included. ${ }^{42,49}$ Girkin, et al., ${ }^{15}$ reported four cases of RON following SRS, two of which occurred in patients treated for pituitary adenoma, of 2400 radiosurgical cases; it is unclear how many patients in the treatment group had pituitary tumors. Three of the four patients received more than 8 Gy to the anterior optic apparatus, prompting the authors to agree with previous reports that the optic nerves and chiasm can tolerate a maximal radiation dose of $8 \mathrm{~Gy},{ }^{15,31,52}$ although others have reported safe doses in the range of 10 to $12 \mathrm{~Gy} .{ }^{26,34,36,49}$ Other risk factors for the development of RON include previous radiation therapy, ${ }^{10}$ pretherapy visual loss, ${ }^{25}$ tumor size greater than 10 $\mathrm{mm},{ }^{12,50}$ and isocenters within $5 \mathrm{~mm}$ of the visual path- ways. ${ }^{50}$ Stafford, et al. ${ }^{49}$ have estimated that the incidence of RON following SRS is $1.7 \%$ if the dose to the chiasm is less than $8 \mathrm{~Gy}, 1.8 \%$ if it is between 8 and $10 \mathrm{~Gy}$, and $6.9 \%$ if it is greater than $12 \mathrm{~Gy}$. The proximity of the optic chiasm to the tumor is not an issue in radiosurgical planning, because the typical microadenoma of Cushing disease is well separated from the optic chiasm. Thus, limiting the exposure of the optic structures to radiation in such patients is usually not difficult (Fig. 3).

The incidence of temporal lobe necrosis following conventional radiation therapy for pituitary adenomas is difficult to determine based on the literature, but it is likely to be between 1 and $5 \% .{ }^{40} \mathrm{In}$ a rigorous discussion of induction of a secondary neoplasm in normal tissues within the irradiated field, an appropriate definition should be used. Radiation-induced neoplasms must meet the following criteria. 1) The tumor must be within the previous field of irradiation. 2) There must be a sufficient interval between the irradiation and the development of the new tumor (typically ranging from many months to years). 3) The histological characteristics of the new tumor must differ from that of the original lesion. 4) The patient must not have a disease associated with the development of new tumors, such as neurofibromatosis, Li-Fraumeni syndrome, on tuberous sclerosis. ${ }^{4}$ The incidence of such a neoplasm induction is approximately 1 or $2 \%$ following conventional radiation therapy for pituitary tumors. ${ }^{37}$ This risk accumulates with time; the actuarial risk is $1.7 \%$ at 10 years and $2.7 \%$ at 15 years. ${ }^{54}$ To our knowledge, two cases of radiation-induced neoplasms have been reported following SRS for pituitary tumors, both in patients with acromegaly; in one of these patients a meningioma developed and in the other a vestibular schwannoma within the field of radiation. ${ }^{28}$ In addition, four patients with radiation-

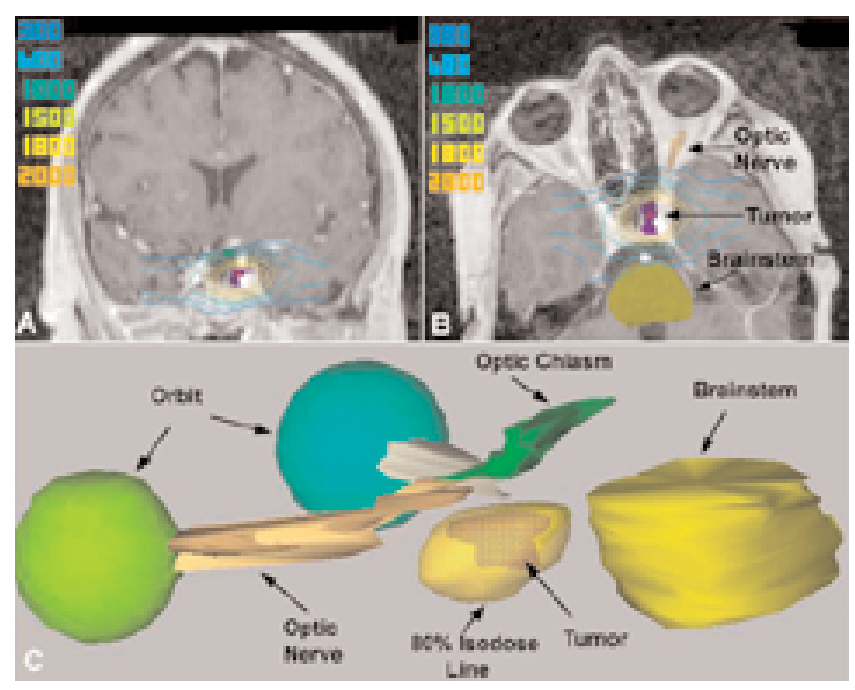

Fig. 3. Radiosurgical dose planning for the patient whose MR image is shown in Fig. 1. Coronal (A) and axial (B) contrastenhanced MR images include an overlay of the isodose curves (300-2000 cGy). The maximum radiation dose was $2284 \mathrm{cGy}$ and the dose prescribed to the tumor margin was 1800 cGy (at the $80 \%$ isodose line). The optic nerves, optic chiasm, and brainstem were outside the 300-cGy isodose line. The relationship of the $80 \%$ isodose line (with its associated dosecloud) to critical structures, particularly the optic chiasm and brainstem, is apparent (C). 
induced neoplasms have been reported following SRS in other regions of the brain. ${ }^{20,44,47,56}$

A $50 \%$ rate of hypopituitarism at 20 years after conventional radiotherapy has been reported for those patients with normal pretreatment endocrine function. ${ }^{27,37}$ Early experience with SRS in which pneumoencephalography was used for targeting produced similar results with respect to pituitary function. ${ }^{18}$ Somatotrophs of the anterior pituitary constitute the cell type most sensitive to the effects of radiation, followed by gonadotrophs, corticotrophs, and thryrotrophs. ${ }^{6,18,27}$ In contemporary series the incidence of new-onset hypopituitarism requiring replacement therapy following SRS has been reported to range between 16 and $55 \%$ with a median period of between 50 and 60 months. ${ }^{7,9,33,51,55} \mathrm{In}$ two of the most recent studies the incidence was reported to be less than $20 \%,{ }^{33,55}$ although in another recent study the incidence was determined to be $41 \% .{ }^{9}$ Feigl, et al., ${ }^{9}$ found that the pituitary stalk received a higher dose of radiation in patients in whom hypopituitarism developed than in those in whom it did not (7.7 Gy compared with 5.5 Gy). Another study found that the safe mean dose of radiation to the hypophysis was $15 \mathrm{~Gy}$ for gonadotropic and thyrotropic function and $18 \mathrm{~Gy}$ for adrenocorticotropic function..$^{55}$

\section{Nelson Syndrome}

The development of a particularly aggressive ACTHproducing adenoma following bilateral adrenalectomy has been termed "Nelson syndrome" and deserves a separate mention. ${ }^{30,35,41}$ For these tumors, which tend to be more invasive, transsphenoidal microsurgery is unlikely to be as successful in obtaining a biochemical cure than it is for typical Cushing disease. Indeed, only five (45\%) of 11 patients with Nelson syndrome experienced disease remission after surgery in one study. ${ }^{21}$ Pollock, et al., ${ }^{41}$ have recently reported their experience with 11 patients who underwent SRS for Nelson syndrome. In this series, tumor growth was controlled in nine patients (82\%). In addition, ACTH levels decreased a median of $66 \%$ and in four patients $(36 \%)$ there was normalization of ACTH levels. The median radiation dose was $20 \mathrm{~Gy}$. Three patients (27\%) experienced a complication, including visual loss and asymptomatic temporal lobe necrosis; because all these patients had been previously treated with conventional radiotherapy, it is difficult to determine the relative contributions of the SRS and standard radiotherapy to these complications. Based on results such as these, it appears that SRS may be an effective treatment for patients with Nelson syndrome. ${ }^{30,41}$

\section{QUESTIONS FOR FURTHER STUDY}

Many questions require thoughtful answers in the growing field of SRS. Obviously, a longer follow-up period and greater experience are required before definitive statements can be made regarding long-term outcomes and complications following SRS. Important questions regarding this therapy of pituitary adenomas need to be clarified before SRS can be definitively recommended as a viable primary therapy for all patients. It is still not clear what is the most appropriate radiation dose, nor whether the maximal dose or that directed to the tumor margin is more important. It does appear, however, that the dose to the tumor margin needs to be greater to achieve an endocrinological cure than it does to attain control of tumor growth. ${ }^{55}$ The margin dose for growth control lies in the range of 18 to $25 \mathrm{~Gy},{ }^{23,55}$ whereas that required for endocrinological control may need to be as high as 35 Gy. ${ }^{7,18,55}$ This has important implications for treating functional adenomas with SRS, because a high rate of tumor cure may be achieved only at the expense of hypopituitarism. In addition, the quality of follow-up data reported for patients treated with SRS in clinical series is poor. The SRS literature is replete with papers containing follow-up results for only a fraction of the actual number of patients treated. In the strictest sense, a report that $45(90 \%)$ of 50 patients were cured with a particular therapy, when in fact 150 patients were treated and 100 were lost to follow up, actually represents $45(30 \%)$ of 150 patients proven to be cured. In addition, the role of repeated treatment with SRS for persistent or recurrent Cushing disease needs to be clarified. Limited initial evidence suggests that repeated treatment is both effective and safe, but further experience is required. ${ }^{7,18}$ Finally, the role of fractionated stereotactic radiotherapy should be addressed. Although fractionation may make biological sense for malignant neoplasms, this is not the case for benign tumors. ${ }^{23}$ It may not make sense to reduce the tumor control rate to achieve a potential decrease in a complication rate when that rate is already so low (particularly for microadenomas).

\section{CONCLUSIONS}

Stereotactic radiosurgery is becoming an increasingly valuable option in the treatment of many patients with diseases suited to neurosurgery. For patients with Cushing disease, the rate of endocrinological cure following SRS appears to be similar to that attained using microsurgical resection. Although the incidence of hypopituitarism postSRS may be higher than that following resection, the incidence of diabetes insipidus is negligible and the treatment is not as invasive. Complications such as RON, temporal lobe necrosis, and induction of a secondary neoplasm are rare following SRS. With some standardization within the radiosurgical literature regarding appropriate dosing and criteria for cure, along with more rigorous follow-up review of all treated patients, it may be possible in the near future to make more definitive statements regarding the use of SRS as an initial treatment for patients with Cushing disease.

\section{References}

1. al-Mefty O, Kersh JE, Routh A, et al: The long-term side effects of radiation therapy for benign brain tumors in adults. J Neurosurg 73:502-512, 1990

2. Bochicchio D, Losa M, Buchfelder M: Factors influencing the immediate and late outcome of Cushing's disease treated by transsphenoidal surgery: a retrospective study by the European Cushing's Disease Survey Group. J Clin Endocrinol Metab 80:3114-3120, 1995

3. Burke CW, Adams CB, Esiri MM, et al: Transsphenoidal surgery for Cushing's disease: does what is removed determine the endocrine outcome? Clin Endocrinol 33:525-537, 1990

4. Cahan WG, Woodard HQ, Higinbotham NL, et al: Sarcoma arising in irradiated bone: report of eleven cases. 1948. Cancer 82:8-34, 1998 
5. Ciric I, Ragin A, Baumgartner C, et al: Complications of transsphenoidal surgery: results of a national survey, review of the literature, and personal experience. Neurosurgery 40: 225-237, 1997

6. Degerblad M, Brismar K, Rahn T, et al: The hypothalamus-pituitary function after pituitary stereotactic radiosurgery: evaluation of growth hormone deficiency. J Intern Med 253: 454-462, 2003

7. Degerblad M, Rahn T, Bergstrand G, et al: Long-term results of stereotactic radiosurgery to the pituitary gland in Cushing's disease. Acta Endocrinol 112:310-314, 1986

8. Estrada J, Boronat M, Mielgo M, et al: The long-term outcome of pituitary irradiation after unsuccessful transsphenoidal surgery in Cushing's disease. N Engl J Med 336:172-177, 1997

9. Feigl GC, Bonelli CM, Berghold A, et al: Effects of gamma knife radiosurgery of pituitary adenomas on pituitary function. J Neurosurg 97 (Suppl 5):415-421, 2002

10. Flickinger JC, Deutsch M, Lunsford LD: Repeat megavoltage irradiation of pituitary and suprasellar tumors. Int J Radiat Oncol Biol Phys 17:171-175, 1989

11. Flickinger JC, Kondziolka D, Maitz AH, et al: An analysis of the dose-response for arteriovenous malformation radiosurgery and other factors affecting obliteration. Radiother Oncol 63: 347-354, 2002

12. Flickinger JC, Lunsford LD, Wu A, et al: Treatment planning for gamma knife radiosurgery with multiple isocenters. Int J Radiat Oncol Biol Phys 18:1495-1501, 1990

13. Flickinger JC, Nelson PB, Martinez AJ, et al: Radiotherapy of nonfunctional adenomas of the pituitary gland. Results with long-term follow-up. Cancer 63:2409-2414, 1989

14. Ganz JC, Backlund EO, Thorsen FA: The effects of gamma knife surgery of pituitary adenomas on tumor growth and endocrinopathies. Stereotact Funct Neurosurg 61 (Suppl 1): 30-37, 1993

15. Girkin CA, Comey CH, Lunsford LD, et al: Radiation optic neuropathy after stereotactic radiosurgery. Ophthalmology 104: 1634-1643, 1997

16. Guilhaume B, Bertagna X, Thomsen M, et al: Transsphenoidal pituitary surgery for the treatment of Cushing's disease: results in 64 patients and long term follow-up studies. J Clin Endocrinol Metab 66:1056-1064, 1988

17. Hayashi M, Taira T, Chernov M, et al: Gamma knife surgery for cancer pain-pituitary gland-stalk ablation: a multicenter prospective protocol since 2002. J Neurosurg 97 (Suppl 5): 433-437, 2002

18. Hoybye C, Grenback E, Rahn T, et al: Adrenocorticotropic hormone-producing pituitary tumors: 12- to 22-year follow-up after treatment with stereotactic radiosurgery. Neurosurgery 49: 284-292, 2001

19. Iwai Y, Yamanaka K, Shiotani M, et al: Radiosurgery for acoustic neuromas: results of low-dose treatment. Neurosurgery 53:282-288, 2003

20. Kaido T, Hoshida T, Uranishi R, et al: Radiosurgery-induced brain tumor. Case report. J Neurosurg 95:710-713, 2001

21. Kemink SA, Grotenhuis JA, De Vries J, et al: Management of Nelson's syndrome: observations in fifteen patients. Clin Endocrinol 54:45-52, 2001

22. Kobayashi T, Kida Y, Mori Y: Gamma knife radiosurgery in the treatment of Cushing disease: long-term results. J Neurosurg 97 (Suppl 5):422-428, 2002

23. Laws ER, Reitmeyer M, Thapar K, et al: Cushing's disease resulting from pituitary corticotrophic microadenoma. Treatment results from transsphenoidal microsurgery and gamma knife radiosurgery. Neurochirurgie 48:294-299, 2002

24. Laws ER Jr, Vance ML: Radiosurgery for pituitary tumors and craniopharyngiomas. Neurosurg Clin N Am 10:327-336, 1999

25. Leber KA, Bergloff J, Langmann G, et al: Radiation sensitivity of visual and oculomotor pathways. Stereotact Funct Neurosurg 64 (Suppl 1):233-238, 1995
26. Leber KA, Bergloff J, Pendl G: Dose-response tolerance of the visual pathways and cranial nerves of the cavernous sinus to stereotactic radiosurgery. J Neurosurg 88:43-50, 1998

27. Littley MD, Shalet SM, Beardwell CG, et al: Hypopituitarism following external radiotherapy for pituitary tumours in adults. Q J Med 70:145-160, 1989

28. Loeffler JS, Niemierko A, Chapman PH: Second tumors after radiosurgery: tip of the iceberg or a bump in the road? Neurosurgery 52:1436-1442, 2003

29. Mampalam TJ, Tyrrell JB, Wilson CB: Transsphenoidal microsurgery for Cushing disease. A report of 216 cases. Ann Intern Med 109:487-493, 1988

30. McCutcheon IE: Stereotactic radiosurgery for patients with ACTH-producing pituitary adenomas after prior adrenalectomy. Int J Radiat Oncol Biol Phys 54:640-641, 2002

31. Mehta MP, Kinsella TJ: Cavernous sinus cranial neuropathies: is there a dose-response relationship following radiosurgery? Int J Radiat Oncol Biol Phys 27:477-480, 1993

32. Morange-Ramos I, Regis J, Dufour H, et al: Gamma-knife surgery for secreting pituitary adenomas. Acta Neurochir 140: 437-443, 1998

33. Morange-Ramos I, Regis J, Dufour H, et al: Short-term endocrinological results after gamma knife surgery of pituitary adenomas. Stereotact Funct Neurosurg 70 (Suppl 1):127-138, 1998

34. Morita A, Coffey RJ, Foote RL, et al: Risk of injury to cranial nerves after gamma knife radiosurgery for skull base meningiomas: experience in 88 patients. J Neurosurg 90:42-49, 1999

35. Nelson DH, Meakin JW, Thorn GW: ACTH-producing pituitary tumors following adrenalectomy for Cushing's syndrome. Ann Intern Med 52:560-569, 1960

36. Ove R, Kelman S, Amin PP, et al: Preservation of visual fields after peri-sellar gamma-knife radiosurgery. Int J Cancer 90: 343-350, 2000

37. Petrovich Z, Jozsef G, Yu C, et al: Radiotherapy and stereotactic radiosurgery for pituitary tumors. Neurosurg Clin $\mathbf{N}$ Am 14:147-166, 2003

38. Plotz CM, Knowlton AI, Ragan C: The natural history of Cushing's syndrome. Am J Med 13:597-614, 1952

39. Pollock BE, Kondziolka D, Lunsford LD, et al: Stereotactic radiosurgery for pituitary adenomas: imaging, visual and endocrine results. Acta Neurochir Suppl 62:33-38, 1994

40. Pollock BE, Nippoldt TB, Stafford SL, et al: Results of stereotactic radiosurgery in patients with hormone-producing pituitary adenomas: factors associated with endocrine normalization. J Neurosurg 97:525-530, 2002

41. Pollock BE, Young WF Jr: Stereotactic radiosurgery for patients with ACTH-producing pituitary adenomas after prior adrenalectomy. Int J Radiat Oncol Biol Phys 54:839-841, 2002

42. Rahn T, Thoren M, Hall K, et al: Stereotactic radiosurgery in Cushing's syndrome: acute radiation effects. Surg Neurol 14: 85-92, 1980

43. Semple PL, Vance ML, Findling J, et al: Transsphenoidal surgery for Cushing's disease: outcome in patients with a normal magnetic resonance imaging scan. Neurosurgery 46:553-559, 2000

44. Shamisa A, Bance M, Nag S, et al: Glioblastoma multiforme occurring in a patient treated with gamma knife surgery. Case report and review of the literature. J Neurosurg 94:816-821, 2001

45. Sheehan JM, Lopes MB, Sheehan JP, et al: Results of transsphenoidal surgery for Cushing's disease in patients with no histologically confirmed tumor. Neurosurgery 47:33-39, 2000

46. Sheehan JM, Vance ML, Sheehan JP, et al: Radiosurgery for Cushing's disease after failed transsphenoidal surgery. J Neurosurg 93:738-742, 2000

47. Shin M, Ueki K, Kurita H, et al: Malignant transformation of a vestibular schwannoma after gamma knife radiosurgery. Lancet 360:309-310, 2002 
48. Snyder PJ, Fowble BF, Schatz NJ, et al: Hypopituitarism following radiation therapy of pituitary adenomas. Am J Med 81: 457-462, 1986

49. Stafford SL, Pollock BE, Leavitt JA, et al: A study on the radiation tolerance of the optic nerves and chiasm after stereotactic radiosurgery. Int J Radiat Oncol Biol Phys 55:1177-1181, 2003

50. Stephanian E, Lunsford LD, Coffey RJ, et al: Gamma knife surgery for sellar and suprasellar tumors. Neurosurg Clin N Am 3:207-218, 1992

51. Thoren M, Rahn T, Guo WY, et al: Stereotactic radiosurgery with the cobalt-60 gamma unit in the treatment of growth hormone-producing pituitary tumors. Neurosurgery 29:663-668, 1991

52. Tishler RB, Loeffler JS, Lunsford LD, et al: Tolerance of cranial nerves of the cavernous sinus to radiosurgery. Int J Radiat Oncol Biol Phys 27:215-221, 1993

53. Trainer PJ, Lawrie HS, Verhelst J, et al: Transsphenoidal resec- tion in Cushing's disease: undetectable serum cortisol as the definition of successful treatment. Clin Endocrinol 38:73-78, 1993

54. Tsang RW, Laperriere NJ, Simpson WJ, et al: Glioma arising after radiation therapy for pituitary adenoma. A report of four patients and estimation of risk. Cancer 72:2227-2233, 1993

55. Vladyka V, Liscak R, Novotny J Jr, et al: Radiation tolerance of functioning pituitary tissue in gamma knife surgery for pituitary adenomas. Neurosurgery 52:309-317, 2003

56. Yu JS, Yong WH, Wilson D, et al: Glioblastoma induction after radiosurgery for meningioma. Lancet 356:1576-1577, 2000

Manuscript received February 17, 2004.

Accepted in final form March 2, 2004.

Address reprint requests to: Ian E. McCutcheon, M.D., Department of Neurosurgery, M. D. Anderson Cancer Center, 1515 Holcombe Boulevard, Unit 442, Houston, Texas 77030-4009. email: imccutch@mdanderson.org. 